\title{
Las novatadas. El maltrato como diversión
}

Autor: Ignacio Fernández de Mata (Ed.)

Editorial: McGraw Hill (Aula Magna)

Año de publicación: 2021

Número de páginas: 290

ISBN: 978-84-18392245

El antropólogo burgalés Fernández de Mata coordina esta obra colectiva que ve la luz al mismo tiempo que la temática se sitúa en la opinión pública por la coincidencia con la publicación del Anteproyecto de Ley de Convivencia Universitaria auspiciado por el Ministerio de Universidades, con el objeto de derogar el vigente Reglamento de Disciplina Académica que data de 1954. Las novatadas universitarias se reproducen cada año en todos los campus de educación superior, perpetuando prácticas de humillación y violencia tan populares como toleradas y cuya existencia se puede encontrar ya en Platón. Muchas de estas vejaciones incorporan un hondo contenido sexual y, con frecuencia, el consumo de elevadas cantidades de alcohol. Sin embargo, la mayoría de estudiantes aceptan las novatadas como algo divertido e incluso como elementos integradores.

El expresivo título del volumen publicado por McGraw Hill anticipa la urgente y necesaria mirada crítica hacia la temática, en una obra de acercamiento multidisciplinar sobre su historia, características y efectos. Las novatadas en la universidad son una cuestión compleja de la que da fe el propio origen del libro que aquí se presenta: la organización de un curso de verano en la Universidad de Burgos en 2019 que tuvo que ser cancelado tras la agresiva campaña de estudiantes en redes sociales, con el apoyo del máximo órgano de representación estudiantil, el Consejo de Alumnos.

El volumen se divide en siete capítulos, además de la introducción y un apartado final con reseñas biográficas de los autores y autoras. Los diferentes epígrafes abordan el fenómeno de las novatadas desde sus aspectos culturales, normativos, psicológicos o de género entre otros, a partir de la realidad española pero en diálogo con una perspectiva internacional.

El primer capítulo - Abusos y traumas: la experiencia de las novatadas - corre a cargo de Loreto GonzálezDopeso, psicóloga y presidenta de la asociación Nomasnovatadas.org. La autora describe, desde su experiencia atendiendo a familias, la violencia de unas prácticas consentidas socialmente e incluso celebradas pero que exponen a altísimos grados de humillación y violencia a quienes acceden a la universidad. La autora argumenta no solo el trauma que las novatadas producen en los individuos que las sufren sino también el daño social que proveen.

Ana Aizpún, por su parte, firma un texto desde el abordaje psicológico. La autora relata cómo, durante mucho tiempo, las novatadas han sido normalizadas e incluso alentadas desde una consideración superficial, que las ha definido como bromas, negando su carácter complejo. En este apartado se definen variables como la jerarquía y el poder que opera entre el alumnado recién llegado y quienes ya forman parte del grupo, además de situar cuestiones básicas como son la existencia de una relación asimétrica, la definición como fenómeno grupal y la función como rito de iniciación, siendo esta última característica la que suele argüirse para su defensa.

Es en este punto donde se sitúa el texto de Ignacio Fernández de Mata — Ni rito ni tradición — negando precisamente su carácter ritual. Para el antropólogo, la característica esencial es la experiencia de poder despótico junto a la imposición de la ley de silencio entre quienes sufren las novatadas. Estas se caracterizan por las implicaciones sexuales y la agresividad, configurando una suerte de tutelaje formativo para disfrutar del maltrato y normalizarlo. En este capítulo se explica, asimismo, la diferencia entre las novatadas en Colegios Mayores y Residencias — generalmente más graves y permanentes en el tiempo- y las que se producen en las aulas y centros de estudio, estas últimas más recientes desde el punto de vista histórico pero cuyo número ha crecido exponencialmente.

Los Colegios Mayores, cuya historia en España se remonta al siglo XV, son justamente el objeto de interés del capítulo firmado por Javier Mérida. El autor repasa la normativa legal para la sanción de conductas que, en España, de momento dependen de un reglamento disciplinario preconstitucional. Y, sobre todo, realiza una aproximación crítica sobre la responsabilidad y complicidad de las instituciones académicas. El jurista termina su epígrafe sugiriendo una serie de propuestas para erradicar las novatadas de la universidad.

Fernández de Mata firma otro capítulo dedicado a la explicación cultural de esta forma de maltrato estudiantil. El autor ofrece un argumentado recorrido histórico por la propia institución universitaria con el objeto de situar su 
análisis sobre un fenómeno de construcción gremial donde el otro (el novato) es brutalizado frente a su contrario (el universitario). Es decir, las prácticas infamantes, dolorosas, crueles y/o humillantes que se aplicaron a lo largo de la historia al estudiantado recién llegado a las universidades europeas deben entenderse como una búsqueda de domesticación, de cierto paso de lo salvaje a lo civilizado, que sin embargo no era otra cosa que la naturalización del abuso.

El capítulo de Carolina Hamodi y Yara de Benito profundiza en la cuestión del bullying en el contexto educativo, aunque dejando clara la existencia de diferencias con las novatadas. Con todo, las autoras enfatizan la escasa atención que se ha prestado desde la investigación a la existencia de este fenómeno en la universidad. Aunque el acoso que existe en las aulas escolares se extiende a las universitarias, apenas conocemos su prevalencia, siendo casi inexistente la literatura dedicada a su prevención y/o erradicación. El texto, en este sentido, ofrece pautas para intervenir en este plano.

Finalmente, la aportación de Marta Fernández Morales —Eran buenos chicos: fraternidades y manadas en los campus estadounidenses - relata la naturalización de la cultura de la violación en las universidades así como las iniciativas que buscan elaborar un contradiscurso ante esta violencia. La violencia sexual, tal y como se recoge en este epígrafe, es cada vez más visible en el contexto español pero la cultura de la violación todavía es escasa en la bibliografía académica en español.

Este libro, por tanto, viene a solucionar una laguna de la literatura académica sobre educación superior. Desde su enfoque crítico plantea la existencia de tolerancia social hacia el maltrato y, a partir de ahí, construye una sólida exposición de las variables más significativas de prácticas consideradas con frecuencia como una tradición pero cuyo nombre debería ser bullying o acoso. Más allá de tópicos, la obra pretende reflexionar sobre la propia práctica y contribuir a un debate crítico y argumentado pero también trabajar para desterrar los abusos. El texto demuestra que las novatadas no son una simple diversión.

María Isabel Menéndez Menéndez Universidad de Burgos mimenendez@ubu.es 